\title{
Delivering multidisciplinary public health in action - the Cardiff Food Strategy case study
}

\author{
Ruth M Fairchild ${ }^{1, *}$ and Maria Z Morgan ${ }^{2}$ \\ ${ }^{1}$ Food Research Consultancy Unit, School of Health Sciences, University of Wales Institute, Cardiff, \\ Western Avenue, Llandaff, Cardiff, CF5 2YB, UK: ${ }^{2}$ Department of Dental Health and Biological Sciences, \\ Dental School, Cardiff University, Cardiff, UK
}

Submitted 10 August 2005: Accepted 14 February 2006

\begin{abstract}
Background: There is an increasing awareness that the provision of healthy food relies on the co-ordinated efforts of a number of diverse disciplines, not merely those traditionally linked with food. This paper documents the development of a food and health strategy, commissioned by the health alliance for the city of Cardiff, and focuses on the areas of sustainability, education and training as well as nutrition, food provision and food safety.

Objective: The aim of the strategy was to increase the uptake of a healthy, safe and sustainable diet for all those living in Cardiff.

Method: The methodology included a rapid appraisal of food initiatives operating within the city, establishing a food and health strategy working group and the production of strategy documentation. Multi-agency collaboration and consultation were key components of the approach.

Results: As the strategy developed, seven action areas became apparent, including education and training, public sector procurement and rewarding excellence. These action areas were incorporated into seven 'action tables', which constitute the core of the strategy. The food and health strategy document was ratified by the Local Health Alliance board in August 2004. But, far greater benefits were realised as a consequence of setting up the strategy working group. Long before the document was written, the strategy process was operating as 'multidisciplinary public health in action'.

Conclusion: The network that comprised the food and health strategy working group was already able to commence delivery of a more integrated approach to food and health within Cardiff.
\end{abstract}

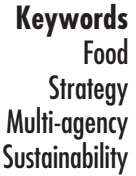

Food provides us with nutrition, forms a central part of our social well-being and provides employment for a large percentage of our community ${ }^{1}$. It is accepted that food and health are inextricably linked. Diseases such as coronary heart disease, obesity, certain cancers and dental caries, and food-borne illnesses such as food poisoning, are dietrelated and improvements in eating habits will enhance the population's health ${ }^{2}$. There is an increasing awareness that the provision of healthy food relies on the coordinated efforts of a number of diverse disciplines, not merely those traditionally linked with food ${ }^{3}$.

UK government public health policy has increased the emphasis on reducing inequalities via addressing the wider determinants of health through multi-agency and multidisciplinary working ${ }^{4,5}$. While there is much literature devoted to outlining the benefits of this approach, there is little documented about the process of delivery. Therefore the present paper documents the process of delivering a food and health strategy for the city of Cardiff, which focuses on the areas of sustainability (tackles social, environmental and economic issues together to ensure that while we meet the needs of the present we do not compromise the outlook for future generations), education and training as well as nutrition, food provision and food safety.

The formulation of food strategies is not isolated to Wales; indeed a number of cities have developed such schemes. These obviously differ in content depending on the requirements of the local population. Examples in the UK include London ${ }^{6}$, where the development agency has devised a food strategy to benefit both the health of the local population and the city's economy, and Greater Merseyside $^{7}$, where the strategy emphasises a coordinated approach to increasing people's access to healthy food. Toronto ${ }^{8}$ in Canada has a food charter which strives to achieve food security for the city, emphasising that all residents should have access to an adequate supply of nutritious, affordable and culturally appropriate food. In Texas, USA the focus includes school nutrition ${ }^{9}$. All of these are predated by the extensive work carried out in the community of North Karelia, Finland ${ }^{10}$ where improvements in diet, achieved by many strategic and policy 
changes, formed a central part of the improvement in public health of the area.

\section{Setting the scene}

Recent changes in health care planning and delivery in Wales created an environment conducive to developing a community-focused food and health strategy. In April 2003, 22 Local Health Boards (LHBs), co-terminus with local councils, were created to encourage greater collaboration between health services and local government ${ }^{11}$. Also, Welsh Councils and LHBs were given a statutory duty to produce and implement Health, Social Care and Well Being Strategies, to address local issues affecting the health and well-being of their residents. In Cardiff, this process was to be facilitated by the Local Health Alliance (LHA), a partnership of the local authority, health service and the voluntary sector.

At this point, the Cardiff Health Alliance commissioned the development of a food and health strategy as part fulfilment of their wider Health, Social Care and Well Being Strategy activities. Food and health was further highlighted because a council member of the LHB had raised food as an issue; it was also raised as key in an audit of local factors influencing the health and well-being of residents ${ }^{12}$, and the food that Cardiff residents eat had scope for being healthier, safer and more sustainable ${ }^{13-16}$.

Cardiff is relatively prosperous in comparison with much of Wales. However, it has some of the most deprived and affluent communities living alongside each other ${ }^{17}$. There are parts of the city which experience inequalities in health; for example, Butetown in South Cardiff has a higher percentage (9.6\%) of low-birth-weight babies than the UK average $(7.0 \%)^{17,18}$. Low birth weight is linked with vascular disease, obesity and non-insulin-dependent diabetes in later life ${ }^{19}$. Poor nutritional intake throughout life is also a predictor of low birth weight in future generations ${ }^{20}$.

The Cardiff food and health strategy was designed from the outset to be more than a 'dust-catcher', i.e. a written document left to gather dust on a shelf. It was intended to facilitate multidisciplinary public health in action.

\section{Method}

The aim of the strategy was to increase the uptake of a healthy, safe and sustainable diet for all those living in Cardiff. This was to be achieved via three main objectives:

1. To undertake a rapid appraisal of food initiatives operating within the city;

2. To recommend membership of, and establish, a food and health strategy working group;

3. To prepare the Cardiff food and health strategy and present it to the Cardiff LHA.

The methodology (summarised in Fig. 1) was guided by the literature, addressing inequalities in health via partnership working and existing good practice in evidenced-based approaches to public health nutrition ${ }^{21-24}$.

Cardiff Health Alliance commissioned a comprehensive needs-assessment exercise which brought together data traditionally held by separate agencies, such as unemployment, crime, education, housing and morbidity. This community profile provided baseline information for subsequent development of the Health, Social Care and Well Being Strategy for Cardiff, including the food and health strategy ${ }^{17}$.

Work on the Cardiff food and health strategy commenced in the spring of 2002 with a qualitative rapid appraisal of existing food initiatives operating within the city. An initial meeting between the authors, the head of the LHB's health promotion department and the LHA co-ordinator provided details of a number of local food initiatives and research. Theoretical sampling was employed to complete the search for additional projects, via initial key informant interviews and subsequent snowball method ${ }^{25}$.

Structured annotated interviews were undertaken with representatives from 26 local food initiatives ${ }^{25}$. Questions were tailored to specific projects. However, broad themes included: duration, scope, sources of funding and geographical area covered by the project. Details were collected of the evidence base associated with the design and implementation of the initiative, as well as information regarding whether the food education delivered by the projects came from accredited sources.

Information gathered during the rapid appraisal and when reviewing the literature on nutrition and food strategies $^{22,26}$ highlighted the importance of five main topic areas, i.e. nutrition, food provision, food safety, food sustainability, and food education and training. Working group representation was sought from these key areas.

The authors, following the rapid appraisal process, devised a framework for the definitive strategy. The framework consisted of the existing coverage and good practice, gaps, challenges and ways of addressing the challenges associated with the food initiatives. The working group used this framework as a starting point when writing the definitive strategy documentation.

The working group met approximately bi-monthly between November 2002 and March 2004 to develop the Cardiff Food Strategy document. The strategy needed to take account of a range of international, UK, Principality and council-wide strategic documents ${ }^{17,27-34}$. The first draft of the strategy document was completed in the spring of 2004.

Consultation formed a key component of the strategy process. In particular, the authors participated in a multiagency and multidisciplinary Health Alliance Exposition. Here, all contributors to the wider fitness, and health, social care and well-being strategies in Cardiff were represented. A second consultation event, specifically for the food and health strategy, allowed input from key 


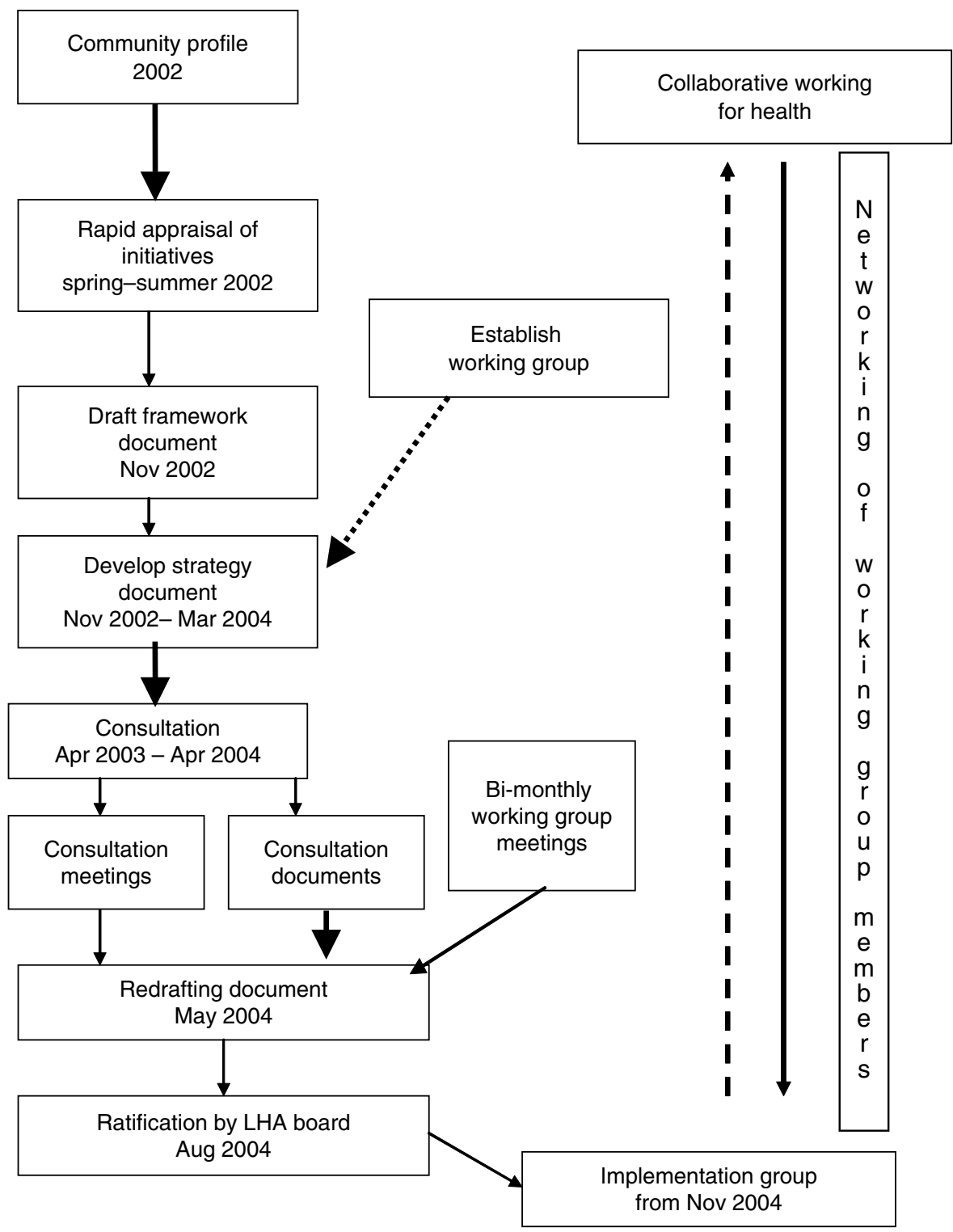

Fig. 1 The Cardiff Food Strategy process. LHA - Local Health Alliance

stakeholders not otherwise represented on the working group. This event involved presentations of good practice and workshops where discussion focused on progressing the food and health strategy objectives.

The strategy document itself went out to consultation, in April 2004, to approximately 100 key stakeholders, including those who had not been able to attend previous consultation events. The document was subsequently redrafted and submitted to the LHA board in the summer of 2004.

\section{Results}

The rapid appraisal identified 26 food initiatives (Table 1). Key findings are presented below; a more detailed account is given elsewhere ${ }^{12,35}$.
There was considerable evidence of good practice. However, initiatives did not always access food and health advice from accredited sources. For example, when interviewing a representative from one local initiative there appeared to be a lack of awareness of accredited materials already available and an over-zealous attitude to preparing them from scratch. Whilst having considerable local knowledge, those involved were not formally trained in nutrition and had not sought accredited guidance.

Interviewee 1: 'We are preparing an updated weaning leaflet, to take account of our local community, which includes Pakistani, Somali and Bangladeshi residents.'

Interviewer: 'Have you had any advice from the community dietetics department on this?'

Interviewee 1: 'No, we've been doing this in-house.' 
Table 1 Food initiatives in Cardiff

Afro-Celtic Education, Culture and Arts Association Somali Food
Project
Barefoot Health Workers Project
Butetown, Grangetown \& South Riverside Sure Start Nutritional
Strategy
Butetown, Grangetown Healthy Living Programme
Cardiff Council Chartered Institute of Environmental Health Food
Hygiene Training
Cardiff Council Sustainable Food, incorporating Cardiff allotments
and Sustainable Schools grants programme
Cardiff Network of Healthy Schools, including the Fruit Tuck Shop
Scheme
Diabetes Health Promotion in Black \& Minority Ethnic
Communities
Ely/Caerau Community Food Initiatives, incorporating the Big G
Cooking Club, Breakfast clubs, Fruit Tuck shops and Food
Hygiene training
Food Dudes - Cardiff
Heart Ely (Ely/Caerau secondary CHD prevention)
Innovate Trust (formerly CUSS) café and farm
National Schizophrenia Trust community farm, St Fagan's
Provision of food to homeless living in Cardiff, various
organisations, e.g. Wallich Clifford Community
Riverside Community Market
South East locality CHD and Diabetes Project
St Mellon's Healthy Living Centre Nutrition Project
St Mellon's Sure Start Nutrition Advice
UWIC Food Industry Centre, Food Hygiene Training
Welsh Food Hygiene Award Scheme

CHD - Coronary Heart Disease; CUSS - Cardiff University Social Services; UWIC - University of Wales Institute, Cardiff.

When interviewing a representative providing for the homeless in Cardiff, concerns were expressed over a lack of training:

Interviewee 2: 'The City Centre team who do a soup run have no food bygiene training.'

In some cases there was a distinct lack of communication between initiatives, other health providers (e.g. health promotion, environmental health and community dietetics) and appropriate local government departments (education, sustainability, social services).

Interviewee 3: 'Not many schools in Cardiff have a healthy eating policy - this could be pushed by a strategy for Cardiff.'

Interviewee 4: 'There's a need to develop local policies to allow the transfer of info between workers from different disciplines.'

A by-product of the rapid appraisal exercise was the production of a computerised database of contacts for Cardiff-based food initiatives, which has been regularly updated throughout the strategy process.

The core working group consisted of representatives from health promotion, community dietetics, environmental health, academia (consumer science, nutrition, and public health), local government, minority ethnic groups, primary care, public health, schools including catering, and sustainable development. In addition, the working group was able to access specialists in consumer advocacy, retail/food production, trading standards and the voluntary sector, via a wider network of contacts.

The strategy document resulting from the process outlined in Fig. 1 consisted of seven action areas:

1. Public Sector Procurement;

2. Large Public Events;

3. Education and Training;

4. Targeted Age Groups;

5. Rewarding Excellence;

6. Cardiff Food 'Industry';

7. Cardiff-wide Strategies.

These action areas were incorporated into seven 'action tables' with subheadings, as presented in Table 2 using the Education and Training strategy area as an example.

The consultation exercises continually informed the methodology associated with the strategy (Fig. 1). The Health Alliance Exposition permitted cross-fertilisation across Health, Social Care and Well Being Strategy working groups (e.g. physical fitness, mental illness, tobacco, drugs, alcohol, homelessness) and the involvement of local community representatives, voluntary sector workers and local councillors.

There were two main outcomes of the food and health consultation event. (1) The benefit of the experience of those working in food initiatives elsewhere which were exemplars of good practice. For example, there was representation from the Powys Food Futures Programme, which supports a sustainable local food economy in rural Wales. (2) The opportunity to inform and lobby Welsh National organisations whose input is influential in policy development and implementation; for example, the Welsh Development Agency, the Food Standards Agency Wales and the Environment Agency.

Approximately $10 \%$ of those sent the consultation document responded, including representatives from the local NHS trust, local Sure Start schemes, council housing advice and benefits, and the Welsh Local Government Association. There was broad support for the strategy documentation.

Consultees were able to highlight areas which required clarification, e.g. there needed to be a greater emphasis on the relationship between statutory and non-statutory sectors. They also raised concerns about securing long-term funding to realise the strategy objectives. This had already been raised as a major issue during both the rapid appraisal exercise and working group deliberations:

Interviewee 3: 'There are currently 36 primary and secondary schools included in the network of healthy schools ... we need to limit the success of the scheme as each school should receive $£ 200$, but at this rate the funding won't cover it! ... Schemes such as the Fruit Tuck Shop need to provide 
Table 2 An example action area incorporated into an 'action table'

\begin{tabular}{|c|c|c|}
\hline Column & & Example content \\
\hline I & Strategy area & Education and Training \\
\hline II & Method of implementation & $\begin{array}{l}\text { E.g. to ensure that food hygiene training is available to all food workers } \\
\text { and handlers }\end{array}$ \\
\hline III & Responsibility for action & $\begin{array}{l}\text { E.g. co-ordinated efforts of the health alliance and primary through tertiary } \\
\text { education }\end{array}$ \\
\hline IV & Resource implications & $\begin{array}{l}\text { Funding required to implement the Education and Training aspects of the } \\
\text { strategy across Cardiff, e.g. officer time, clerical assistance, cost of } \\
\text { producing and disseminating materials }\end{array}$ \\
\hline V & Goals & $\begin{array}{l}\text { E.g. improve the consistency and accuracy of advice given on all areas } \\
\text { relating to food }\end{array}$ \\
\hline VI & Monitoring and evaluation & $\begin{array}{l}\text { (In terms of short, medium and long term): e.g. in the short term produce a } \\
\text { corporate Food Handlers' Fitness to Work policy by Summer } 2005\end{array}$ \\
\hline
\end{tabular}

supply cover ( 150 per half day) for teachers to attend training.'

'Like other HSCWB strategy working groups (e.g. tobacco control) Cardiff Food Strategy is not resource-neutral ... whilst some items in action tables come from peoples' jobs, the synergism between them needs a belping hand.'

The main tangible outcome of the process has been the production of a food and health strategy document for Cardiff, which was ratified by the LHA board on the 24 th August 2004 (see Fig. 1). However, far greater benefits have been realised as a consequence of the setting up of a multidisciplinary, multi-agency strategy working group. Some outcomes of the process achieved, before the strategy document was finalised, include:

- A greater understanding of multi-sectoral food issues through discussion and debate and engagement of a wider range of partners in a wider network.

- A proforma was devised to collate details of the Cardiff food projects. This was adapted from one originally developed by Cardiff housing department to provide information on initiatives associated with the homeless $^{31}$.

- Members of the working group jointly applying for New Opportunities (lottery) Funding, strengthening their applications by including Cardiff food and health strategy objectives.

- A more effective working relationship between the schools catering service, Cardiff Network of Healthy Schools Scheme and the LHB's health promotion and community dietetics departments.

- Environmental health and community dietetics working towards a more co-ordinated approach to food hygiene training for Cardiff food workers from the voluntary sector and local food initiatives.

- Council sustainability officers, community dietetics and regulatory services collaborating to ensure information regarding food is integrated in terms of nutrition, food safety and sustainability.

- A placement student from University of Wales Institute, Cardiff was employed by Cardiff LHB to collate and evaluate information suitable for inclusion in a resource pack to be used as part of the education and training component of the strategy.

\section{Discussion}

The Cardiff food and health strategy is unique in that it refers to food in its widest sense. The issues of sustainability, food safety, food provision, education and training are all inherent within it. This is in keeping with the recommendation of Margetts et al. ${ }^{22}$ that policies should be driven by health and consider wider issues like ecological sustainability. Thus, the Cardiff strategy is broader than other local and national food strategies. For example, when Snowdon and Edwards ${ }^{36}$ described their experiences of a multi-agency food strategy in Bedfordshire there was no mention of sustainability issues. More recently, the Food and Well Being Strategy of the Food Standards Agency Wales $^{34}$ focuses primarily on nutrition with food hygiene and sustainability being largely absent.

Our methodology was based on evidence addressing inequalities in health via partnership working, and existing good practice in public health nutrition ${ }^{21-24}$. However, this information was largely focused on the macro level, as opposed to the practicalities of delivering a multi-agency strategy for a local community, for which only one reference was found ${ }^{36}$.

The rapid appraisal provided a framework for the strategy, in particular the seven action areas. It also highlighted a lack of communication between local initiative workers, which resulted in duplication of effort and in some instances a lack of awareness of the need for accredited training.

The seven strategy action areas were selected as they reflected both national and local priorities in relation to reducing inequalities in health via food-related initiatives. Public Sector Procurement provides an opportunity for an integrated approach to food. For example, Cardiff Council employs 15000 people. Changes within this sector should improve the health not only of these workers, but also all of those living in residential and care homes and attending schools, nurseries and council venues. Pooling resources, 
such as manpower, facilities and equipment, has potential to achieve expenditure efficiencies and reduce wastage of time and resources.

The strategy area focusing on Large Public Events evolved because Cardiff has staged a series of national and international events in recent years, such as the 1998 European Summit and the Rugby World Cup in 1999. Food safety, provision, sustainability, and education and training will be considered when planning major events taking place in the city.

The provision of high-quality 'food' education and training is key to the Cardiff food and health strategy. All food initiatives need appropriately trained workers, supported by accredited professionals, to avoid the mixed messages and inconsistencies highlighted in the rapid appraisal.

The action area Targeted Age Groups was influenced by the demography of the city ${ }^{17}$. Infants, children and young people are targeted, building upon the work of Cardiff Council's Breast Feeding Strategy, the Cardiff Network of Healthy Schools, local Sure Start and Healthy Living Programmes within the city. The strategy also focuses on the elderly, especially those in residential homes.

A Welsh food hygiene award scheme successfully operates within Cardiff. The strategy aims to extend this award to include all aspects of food, i.e. sustainability, nutrition, education and training as well as food safety, in its Rewarding Excellence strategy area.

Cardiff Food 'Industry' refers to all providers of food to the Cardiff population, irrespective of where that food comes from. This embraces everything from the larger manufacturers, through local producers to community initiatives such as 'box' schemes.

It is imperative that food in its widest sense is prominent in all relevant Cardiff-wide strategies and this is the focus of the final area. The ultimate goal will be to raise the profile of food on the local political agenda.

Now that the strategy document has been ratified by the LHA board, the working group has been charged with developing an implementation plan. At this stage progress is being made on all the resource-neutral aspects of the strategy. A potential barrier to the success of the Cardiff Food Strategy is the sourcing of appropriate funding and workforce. While some objectives can and have been achieved through more effective joint working practices, one of the benefits of multi-agency working, other work requires specific dedicated resources. Consequently, realising the strategy's long-term aim of raising the profile of food on the political agenda is crucial to the successful implementation of the strategy. Resources are more likely to be made available now that common goals and ground have been established by the strategy.

Gilmore's ${ }^{37}$ concerns that multi-agency working is more rhetoric than reality may come true because the multiagency strategy process cannot be achieved without adequate funding ${ }^{38}$ and requires a considerable time commitment to progress (Fig. 1). The strategy document consultation process, for instance, involved two mail shots and some telephone follow-up and yet yielded only a 10\% response rate. The food strategy working group has proposed a more active and targeted lobbying of key target individuals to help with the implementation stage this will require considerable commitment, time and effort. Unless there is central co-ordination, efforts to work in local partnerships with other agencies can be seriously jeopardised ${ }^{37}$. The LHA has taken the lead in commissioning a range of integrated health strategies, including social care and well-being, physical activity and food and health. Their lead has been influential in delivering 'multidisciplinary public health in action' as evidenced by the collaboration of the Cardiff food and health working group outlined above. To deliver 'reality as opposed to rhetoric' therefore, Welsh LHAs must be allowed to continue their co-ordinating role, ensuring food fits into an overall strategic plan which is adequately resourced ${ }^{38}$.

\section{Conclusion}

The work of the Cardiff food and health working group has so far been successful in achieving its original objectives and is making progress towards the overall aim of increasing the uptake of a healthy, safe and sustainable diet for all those living in Cardiff. We have documented the working group's progress towards a food and health strategy to share our approach and experiences.

The Cardiff food and health strategy is attempting to address the wider determinants of health associated with food and nutrition to 'add years to life and life to years, 39 for those living in the Welsh capital. The strategy has started to deliver this because it constitutes multidisciplinary public health in action.

\section{Acknowledgements}

The authors would like to acknowledge the assistance of the Cardiff food and health strategy working group and other multi-agency partners who contributed to the strategy. Also, we thank Ms Meera Patel for collating food initiative details using the proforma.

Working Group Members (excluding authors): Peter Draper, Sue Eakers, Christine Jenkins, Judith John, Mark Lancett, Sarah Lart, Yvonne McMeel, Alan Netherwood, Eryl Powell, Judith Sargant, Eirian Thomas, Alastair Tomlinson and Bruce Whitear.

This work was financed by a grant from the Cardiff Health Alliance.

\section{References}

1 Office of National Statistics. In: Hitchman C, Christie I, Harrison M, Lang $\mathrm{T}$, eds. Inconvenience Food. The 
Struggle to Eat Well on a Low Income. London: Demos, 2002; 53.

2 Willett WC. Nutritional Epidemiology. Monographs in Epidemiology \& Biostatistics. New York: Oxford University Press Inc., 1998

3 McGlone P, Dobson B, Dowler E, Nelson M. Food Projects and How They Work. York: Joseph Rowntree Foundation, 1999.

4 Department of Health. Choosing Health: Making Healthier Choices Easier. London: Department of Health, 2004.

5 Welsh Assembly Government. The Welsh Assembly Government's Health, Social Care and Well Being Agenda [online], 2005. Available at http://www.wales.gov.uk/subihealth/ hscwb/hscwb-page1-e.htm. Accessed 6 August 2005.

6 London Development Agency. A Food Strategy for London, Final Draft [online], 2005. Available at http://www.lda.gov. uk/upload/pdf/London_Food_draft_strategy.pdf. Accessed 11 January 2006.

7 Heart of Mersey. A Food Charter for Greater Merseyside [online], 2005. Available at http://www.heartofmersey.org.uk/ uploads/documents/hm_yPVk_Food_Ch1.pdf. Accessed 11 January 2006.

8 Toronto City Council. Toronto's Food Charter [online], 2001. Available at http://www.toronto.ca/food_hunger/pdf/ food_charter.pdf. Accessed 11 January 2006.

9 Combs S, Texas Department of Agriculture. Texas Public School Nutrition Policy [online], 2004. Available at http://www.agr.state.tx.us/foodnutrition/ policy/food_nutrition_policy.pdf. Accessed 11 January 2006.

10 Pietinen P, Lahti-Koski M, Vartiainen E, Puska P. Nutrition and cardiovascular disease in Finland since the early 1970s: a success story. Journal of Nutrition, Health \& Aging 2001; 5(3): $150-4$.

11 NHS Cymru Wales. Improving Health in Wales - A Plan for the NHS with its Partners. Cardiff: National Assembly for Wales, 2001

12 Fairchild RM, Morgan MZ. Cardiff Food Strategy. Draft Framework [unpublished], 2002. Available from rfairchild@ uwic.ac.uk or mzmorgan@cardiff.ac.uk

13 Welsh Office. The Welsh Health Survey 1995. Cardiff: Government Statistical Service, 1996.

14 National Assembly for Wales. Welsh Health Survey 1998. Results of the Second Welsh Health Survey. Cardiff: Government Statistical Service, 1999. Also available at http://www.wales.gov.uk/polinifo/health/keypubs/

15 Thomas E (Environmental Health Officer, Regulatory Services, Cardiff), personal communication, 2003.

16 Collins A, Flynn A. Measuring Sustainability: The Role of Ecological Footprinting in Wales, UK. Working Paper Series, No. 22. Cardiff: BRASS Centre, 2004.

17 Cardiff Council. Cardiff Community Profile [online], 2002. Available at http://www.cardiff.gov.uk/content.asp? Parent_Directory_id=2865\&nav $=2867,2904,3441,3580$. Accessed 25 August 2006.

18 Health Development Agency. Low Birth Weight Briefing [online], 2004. Available at http://www.hda.nhs.uk/hdt/ 0803/evidence.html. Accessed 20 April 2005.

19 Barker DJ. The developmental origins of adult disease. European Journal of Epidemiology 2003; 18(8): 733-6.

20 James WPT, Nelson M, Ralph A, Leather S. Socioeconomic determinants of health. The contribution of nutrition to inequalities in health. British Medical Journal 1997; 314(7093): 1545-9.

21 Hawe P, Stickney EK. Developing the effectiveness of an intersectoral food policy coalition through formative evaluation. Health Education Research 1997; 12(2): 213-25.
22 Margetts B, Warm D, Yngve A, Sjöström M. Developing an evidenced-based approach to Public Health Nutrition: translating evidence into policy. Public Health Nutrition 2001; 4(6A): 1393-7.

23 Stockley L. Toward public health nutrition strategies in the European Union to implement food based dietary guidelines and to enhance healthier lifestyles. Public Health Nutrition 2001; 4(2A): 307-24.

24 Pelletier D, McCullum C, Kraak V, Asher K. Participation, power and beliefs shape local food and nutrition policy. Journal of Nutrition 2003; 133(1): 301S-4S.

25 Oppenheim AN. Questionnaire Design, Interviewing and Attitude Measurement, new edition. London: Pinter Publishers, 1992; 43.

26 Food Standards Agency Wales and Welsh Assembly Government. Nutrition Strategy for Wales Consultation Document. Cardiff: Food Standards Agency Wales, 2002.

27 World Health Organization (WHO). Integrated Prevention of Non-communicable Diseases - Draft Strategy on Diet, Physical Activity and Health. EB113/44 Add. 1. Geneva: WHO, 2003.

28 British Nutrition Foundation. Balance of Good Health [online], 2002. Available at http://www.nutrition.org.uk/ home. asp? siteId $=43 \&$ sectionid $=874 \&$ subSectionid $=320 \&$ parentSection $=299 \&$ which $=1$. Accessed 25 August 2006 .

29 Cardiff Council. Cardiff Sustainability Strategy [online], 2000. Available at http://www.cardiff.gov.uk/sustainabledevelopment/content.asp?nav $=4118 \&$ parent_directory_id $=3148 \&$ positioning_article_id $=\&$ language $=\&$ sortkey $=$. Accessed 25 August 2006.

30 Cardiff Council. A Community Strategy for Cardiff [online], 2004. Available at http://www.cardiff.gov.uk/content. asp?nav $=2867,3600,3650$ \&parent_directory_id $=2865 \&$ Positioning_Article_ID $=\&$ language $=\&$ sort key $=$. Accessed 25 August 2006.

31 Welsh Assembly Government. Routes to Reform - A Strategy for Primary Dental Care in Wales. A Consultation Document of the Health and Well-being Strategy and Planning Team. Cardiff: Welsh Assembly Government, 2002.

32 National Assembly for Wales. Tackling CHD in Wales: Implementing Through Evidence. National Assembly for Wales: Cardiff, 2001. Also available at http://www.wales. nhs.uk/sites/documents/442/coronary\%2Dheart\%2Ddisease $\% 2$ De $\% 2$ Epdf

33 National Assembly for Wales. National Service Framework for Diabetes (Wales) Standards. National Assembly for Wales: Cardiff, 2002. Also available at http://www.wales. nhs.uk/sites/documents/334/diabetes-standards-wales.pdf

34 Food Standards Agency Wales and Welsh Assembly Government. Food and Well Being Reducing Inequalities Through a Nutrition Strategy for Wales. Cardiff: Food Standards Agency Wales, 2003.

35 Morgan MZ, Fairchild RM, Whitear B, Jenkins C. Development of a food and health strategy for Cardiff. Presented at IADR/AADR/CADR 83rd General Session, Baltimore, MD, 9-12 March 2005. Also in Journal of Dental Research 2005; 84(Special Issue A): abstract no. 773.

36 Snowdon W, Edwards D. A taste for health: the development of a multi-agency food strategy. International Journal of Health Promotion and Education 1999; 37(1): 16-8.

37 Gilmore AB. Joint working, reality or rhetoric? Journal of Public Health Medicine 2001; 23(1): 5-6.

38 Dowler E, Caraher M. Local food projects: the new philanthropy? Political Quarterly 2003; 74: 57-65.

39 Lalonde M. A New Perspective on the Health of Canadians: A Working Document. Ottawa: Ministry of Supply and Services Canada, 1974. 